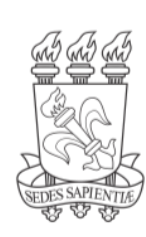

Voluntas, Santa Maria, v.12, n.1, p. 01-15, jan/abril, 2021 • https://doi.org/10.5902/2179378664544

Submissão: 02/03/2021 • Aprovação: 16/03/2021 • Publicação: 26/04/2021

Nietzsche na fenomenologia

\title{
Entre Nietzsche e Husserl: Foucault na Encruzilhada
}

\author{
Between Nietzsche and Husserl: Foucault at the crossroad
}

\author{
Marcos Nalli' \\ ' Universidade Estadual de Londrina (UEL), Londrina, Paraná, Brasil
}

\section{RESUMO}

Pretende-se tensionar a tese, difundida no Brasil de que Foucault é um filósofo nietzschiano, mostrando que seu pensamento pode e deve ser visto sempre em confluência com outros pensadores, formando o que se pode chamar de uma comunidade de pensamento. Para isso, busca-se mostrar a singularidade do pensamento de Foucault, seja em relação àquele de Nietzsche, seja a de Husserl, acentuando alguns de seus pontos de convergência e divergência.

Palavras-Chaves: Foucault; Nietzsche; Husserl

\section{ABSTRACT}

It is intended to tension the thesis, widespread in Brazil that Foucault is a Nietzschean philosopher, showing that his thinking can and should always be seen in confluence with other thinkers, forming what can be called a community of thought. To this end, we seek to show the singularity of Foucault's thought, whether in relation to that of Nietzsche or Husserl, emphasizing some of its points of convergence and divergence.

Keywords: Foucault; Nietzsche; Husserl

\section{INTRODUÇÃO}

Há uma tendência bastante corriqueira entre os leitores de Foucault, ao menos no Brasil, em muito prontamente associá-lo ao pensamento nietzschiano numa linha de relação filial. Há alguns anos tentei - num paradoxo de humildade e presunção - me rebelar a esse gênero de interpretação. Qual era, e ainda é para mim, o problema que 
vejo nele? Justamente a da relação filial. Explico: muito facilmente se diz que Foucault é, pura e simplesmente, nietzschiano. E isto é bem facilitado pelo próprio filósofo francês que também o diz: "sou simplesmente nietzschiano, e tento ver, na medida do possível, sobre certo número de pontos, com a ajuda de textos de Nietzsche - mas também com teses antinietzschianas (que são completamente nietzschianas!) o que se pode fazer neste ou naquele domínio".

Mas será que realmente podemos dar crédito a Foucault? Será que concordar com ele aqui não é, justa e infelizmente, deixar de compreendê-lo em sua singularidade e originalidade de pensamento? A adoção de um termo para adjetivar, para qualificar um pensamento como o de Foucault é, assim me parece, enviesá-lo com vistas a determinado tipo de leitura, de interpretação, cujos parâmetros hermenêuticos certamente propiciam esclarecimentos benfazejos de seu pensamento, de sua escrita, de sua ação docente e de pesquisador, de sua militância (ou mesmo de sua ausência). Mas ao mesmo tempo cria limites interpretativos que podem impedir a compreensão de outros tantos aspectos em todas essas frentes de sua existência. O qualificativo expresso pelo termo "nietzschiano" depende de uma lógica bizarra de claro-escuro em que aspectos se evidenciam a custas de outros que se anuviam, obnubilam ou sequer se notam. Neste sentido, vê-se que a adjetivação do pensamento foucaultiano, sua qualificação como nietzschiano sofre de uma dupla bizarrice: De um lado um pensador da envergadura de Nietzsche que jamais desejou ser mestre de alguém; e do outro, um pensador que jamais se vergou a algum mestre, que alegremente sempre se insubordinou. No entanto, é preciso reconhecer que há alguma relação, como a formar uma espécie de comunidade de pensamento.

Para complicar ainda mais as coisas, é preciso reconhecer que, ao se tentar entender as investidas filosóficas de Michel Foucault, deparamo-nos com uma multifacetada relação com diversos pensadores. E um adequado apanhado dessa plêiade intelectual quase beira à impossibilidade hermenêutica do pensamento foucaultiano. Mas a sua consideração numa linha de cruzamento pode ser bastante 
interessante para compreender como muito livremente Foucault transita de um ponto a outro para produzir suas considerações filosóficas.

Assim, quero contribuir aqui justamente buscando tecer algumas análises tendo como elemento diretriz um desses tantos cruzamentos possíveis, ainda que um tanto improváveis. Quero, então, considerar alguns elementos do pensamento foucaultiano à força do cruzamento do pensamento de Edmund Husserl e Friedrich Nietzsche. O que singulariza a dificuldade por outra razão: notoriamente, a filosofia foucaultiana também é compreendida como um espécie de reação à voga fenomenológica, tão forte na França durante os anos 50 do século passado - e muito provavelmente ainda hoje o é - ao ponto de Gerard Lebrun (1989), comentando Les mots et les choses (1966), toma-o como uma anti-Krisis, numa evidente referência à Krisis de Edmund Husserl, publicado em 1936. No entanto, é possível dizer da ambivalência foucaultiana diante da fenomenologia pela qual ela é um motivo a seu pensamento: “É possível dizer, neste sentido, que Foucault esteve às voltas com a fenomenologia e sua herança - em graus diversos de intensidade - desde suas primeiras obras até suas últimas intervenções no debate intelectual" . E a nosso ver, o ponto importante aqui é o lugar que ainda cabe à significação para Foucault, sendo que para ele o que há de mais problemático na fenomenologia desde Husserl é a aceitação inconteste do estatuto paradigmático da consciência subjetiva como constituinte e referência primeva à significação e ao conhecimento.

Mas comecemos por um dos polos deste improvável cruzamento: Nietzsche, ou melhor, de como Foucault lê Nietzsche. Obviamente, há que se considerar um dos textos mais famosos de Foucault e pelo qual, certamente, muitos se valem para justificar a qualificação nietzschiana de seu pensamento. O texto em questão é "Nietzsche, a genealogia, a história" [“Nietzsche, la généalogie, l'histoire"], publicado em 1971, texto originalmente publicado numa homenagem póstuma ao filósofo hegeliano Jean Hyppolite. Texto famoso pelo qual Foucault busca deslindar terminologicamente o modo de operação próprio da genealogia nietzschiana, "meticulosa e pacientemente 
documentária", que em sua proximidade à história não se lhe opõe e sim, "ao contrário, desdobramento metahistórico das significações ideais e das indefinidas teleologias. Ela [a genealogia] se opõe à busca da 'origem"'.

Para dar conta, Foucault observa que há dois empregos nietzschianos à palavra Ursprung: um que não é marcado, utilizado em alternância com outros termos (Entstehung, Herkunft, Abkunft, Geburt); e outro, marcado, pelo qual o termo Ursprung é utilizado em oposição à Herkunft. Um dos textos de Nietzsche, segundo Foucault, mais importante para o tema e para o uso que o filósofo alemão faz dos termos é a Genealogia da Moral, texto de 1887, no qual ele discorre sobre a "origem dos prejuízos morais" - que alguns tradutores preferem fazê-lo por "procedência", como na tradução italiana das suas Obras Completas [Opere], a famosa e ortodoxa edição Colli e Montinari com tradução de Ferruccio Masini, ou ainda a espanhola com a tradução de Andrés Sánchez Pascual - e que Nietzsche afirma não ser sua primeira investida, remetendo-a, antes, a Humano, demasiado humano .

A partir dessa aparente oposição entre Herkunft e Ursprung, que parece também oscilar entre Humano, demasiado humano (1876-7) e Genealogia da moral (1887) Foucault tece algumas perguntas fundamentais à sua leitura de Nietzsche bem como para a determinação metodológica de seu próprio fazer analítico, sendo talvez, a primeira a mais importante: "Porque Nietzsche genealogista recusa, ao menos em certas ocasiões, a busca pela origem (Ursprung)?" . Pergunta fundamental para marca a cesura entre história e metafísica e sua adesão à identidade originária das coisas: a se recorrer à história, o que se encontra por detrás das coisas não uma identidade, mas outra coisa totalmente outra, isto é a diferença em termos diacrônicos entre passado e presente, mas também se encontra outra coisa, isto é, a discórdia e o disparate, o baixo imodesto das coisas. Daí a ironia inerente às pesquisas genealógicas dos valores morais e da verdade; mas a partir dessa ironia genealógica, desvela-se o rebuliço corpóreo da história. 
Fazer a genealogia [...] será, ao contrário, deter-se nas meticulosidades e nos acasos dos começos; prestar uma atenção escrupulosa em sua derrisória maldade; esperar para vê-los surgir, máscaras finalmente retiradas, com o rosto do outro; não ter pudor de ir buscá-los lá onde eles estão, "escavando as profundezas"; [...] O genealogista tem necessidade da história para conjurar a ilusão da origem [...] É preciso saber reconhecer os acontecimentos da história, seus abalos, suas surpresas, as vacilantes vitórias, as derrotas mal digeridas que dão conta dos começos, dos atavismos e das hereditariedades [...] A história, com suas intensidades, seus desfalecimentos, seus furores secretos, suas grandes agitações febris, assim como suas síncopes, é o próprio corpo do devir. É preciso ser metafísico para procurar sua alma na idealidade longínqua da origem ${ }^{1}$.

É o que, de modo análogo encontramos, por exemplo, na Genealogia da moral, Tratado primeiro ("Bom e malvado", "bom e mau") "Mas voltemos atrás: o problema da outra origem do 'bom', o problema do bom tal como se the imaginou o homem do ressentimento exige chegar a seu final"2; qual seja, a de postular um duplo absurdo: por um lado exigir que a fortaleza nada tenha que ver com a dominação e o subjugo; e por outro lado, subverter a debilidade, a fraqueza num mérito e numa virtude, isto é, em liberdade. Ou ainda, mais adiante, quando o filósofo alemão trata da responsabilidade considerada genealogicamente: “Esta é cabalmente a larga história da procedência ${ }^{3}$ da responsabilidade aquela tarefa de criar um animal a que seja lícito fazer promessas inclui em si como condição e preparação, segundo o que já compreendemos, a tarefa mais concreta de fazer antes ao homem, até certo grau, necessário, uniforme, igual entre os iguais, ajustado à regra e, em consequência, calculável"4, cuja responsabilidade se dá pelo homem soberano o nome de consciência 5 . E o que se depreende genealogicamente da consciência? Uma proveniência totalmente outra que a "boa" consciência e a responsabilidade moral do homem, dissimulada e apagada na memória de nosso tempo presente, em nossa memória moderna, e que

\footnotetext{
${ }^{1}$ FOUCAULT, Dits et écrits, II, 84, 140.

2 NIETZSCHE, Opere, Vol. 6, tomo II, Prima dissertazione, 13, 245; NIETZSCHE, Genealogía de la moral, $13,53$.

${ }^{3}$ Embora seguimos aqui a tradução espanhola, a italiana usa o termo "origem".

${ }^{4}$ NIETZSCHE, Opere, Vol. 6, tomo II, Seconda dissertazione, 2, 256s; NIETZSCHE, Genealogía de la moral, Tratado segundo, 2, 67.

${ }^{5}$ NIETZSCHE, Opere, Vol. 6, tomo II, Seconda dissertazione, 2, 258; NIETZSCHE, Genealogía de la moral, Tratado segundo, 2, p. 68.
}

Voluntas, Santa Maria, v.12, n.1, p. 01-16, jan./abril, 2021 
nada mais é que a má consciência, a consciência de culpa, fundada na concepção enganosa da razão:

Com ajuda de tais imagens e procedimentos se acaba por reter na memória cinco ou seis "não quero", em relação aos quais se expressou a própria promessa com o fim de viver entre as vantagens da sociedade - e realmente, graças a esta espécie de memória, se chega enfim "à razão"! - Ah, a razão, a gravidade, o domínio sobre os afetos, todo este sombrio assunto que se chama reflexão, todos esses privilégios e adornos do homem: quão caros se tem que pagar" quanto sangue e horror há no fundo de todas as "boas coisas"!..." ${ }^{6}$.

Por estes parcos exemplos é possível vislumbrar quais as pretensões nietzschianas ao empreender genealogicamente uma análise da origem (Ursprung) e o pronto resgate crítico da proveniência histórica (Herkunft). Trata-se de dissolver os encantamentos de uma memória à história que faz-nos crer na falsa narrativa de uma origem nobre aos valores culturais, morais e civilizatórios, profundamente - portanto "esquecidos" - e herdados de uma espécie de barbárie primordial; por isso Nietzsche parece sugerir que o fazer genealógico é quase uma pré-história, ou o resgate de uma pré-história, na qual ainda não há a relação enfeitiçada entre memória e história. Como afirma Alexandre Filordi de Carvalho, a tarefa da genealogia “[...] é reorientar a atenção para os fatos ignorados e sórdidos de nossa constituição: o quanto há de cruel, de primitivo, de perverso, de sanguinário, de dominação e de sujeição nesta humanidade"7. $\mathrm{E}$, de certo modo, é neste sentido que se pode ler o trabalho teórico-intelectual de Foucault numa linha de continuidade àquele de Nietzsche, até mesmo de sua atualização. Linha de raciocínio seguida de muito perto por diversos leitores de Foucault no Brasil, ao ponto de se poder tomá-lo como um dos herdeiros de Nietzsche ${ }^{8}$, ou de uma presença nietzschiana no pensamento foucaultiano que vai para bem além da mera afinidade ${ }^{9}$. E que, obviamente, não há de minha parte razão, nem motivos e nem argumentos satisfatórios para negar. Mas é unívoco e incontestável tal posição?

\footnotetext{
${ }^{6}$ NIETZSCHE, Opere, Vol. 6, tomo II, Seconda dissertazione, 3, 260; NIETZSCHE, Genealogía de la moral, Tratado segundo, 3, 71.

${ }^{7}$ CARVALHO, Foucault, 225.

${ }^{8}$ Cf. ARALDI e VALEIRÃO, Os herdeiros de Nietzsche.

${ }^{9} \mathrm{Cf}$. PINHO, A presença de Nietzsche na obra de Foucault.
} 
Não existe aí o risco de se obliterar a originalidade e prodigalidade do diálogo entre Nietzsche e Foucault de modo a identificar o que há no segundo de singular em relação ao primeiro?

Como é possível atestar, de qualquer modo, Foucault parece radicalizar o sentido histórico da genealogia nietzschiana. Se em Nietzsche a genealogia das origens, ou proveniências, de nossos valores morais parece remeter a uma espécie de pré-história, isto é, de uma descoberta polêmica do que foi, memorial e historicamente esquecido, indicando que o índice de polêmica reside exatamente nessa valoração dos valores morais a ser criticada e denunciada. Afinal, "talvez não haja, na pré-história inteira, nada mais terrível e sinistro que sua mnemotécnica" ${ }^{10}$. Urge assim apreender o que caracteriza, segundo Foucault, em Nietzsche o sentido histórico e a história efetiva. Dentre as características identificadas por Foucault, é digna de nota a última, aquela em que se define a história por seu perspectivismo: "[...] é um olhar que sabe de onde olha, assim como o que olha. O sentido histórico dá ao saber a possibilidade de fazer, no próprio movimento de seu conhecimento, sua genealogia"11, e como tal, o que se revela é que o historiador é um tipo de asceta ${ }^{12}$ e que, portanto, conspira com aquela mnemotécnica que traveste de nobreza moral o que outrora era fraqueza ridícula. Contra os historiadores e sua metafísica fundacional, há que se fazer efetivamente história, quer dizer sob a perspectiva genealógica: parodiando as crenças numa nobreza originária, dissolvendo a falsa linha de continuidade entre passado e presente de modo a evidenciar a fortuidade dos acasos, e por fim a oposição entre conhecimento e verdade, de modo a dissolvê-la e, assim, "fazer da história uma contramemória"13.

\footnotetext{
${ }^{10}$ NIETZSCHE, Opere, Vol. 6, tomo II, Seconda dissertazione, 3, 258s; NIETZSCHE, Genealogía de la moral Un escrito polémico, Tratado segundo, 3,. 69.

11 FOUCAULT, Dits et écrits, II, 84, 150.

12 FOUCAULT, Dits et écrits, II, 84, 151.

${ }^{13}$ FOUCAULT, Dits et écrits, II, 84, 153.
} 
Ao proceder assim, há como se notar que, apesar de alguns traços distintivos, há uma linha de continuidade entre a arqueologia e a genealogia em Foucault. E isto tem a ver com o modo como ele considera a história e como a faz operar analítica e criticamente. Vejamos como Roberto Machado, num texto já clássico dentre os comentadores de Foucault sobre a diferença entre a arqueologia e a genealogia:

\begin{abstract}
Seu objetivo [isto é, de Foucault] não é principalmente analisar as compatibilidades e incompatibilidades entre os saberes a partir da configuração de suas positividades; o que pretende é, em última análise, explicar o aparecimento de saberes a partir de condições de possibilidade externas aos próprios saberes, ou melhor, que imanentes a eles - pois não se trata de considerá-los como efeito ou resultante - os situam como elementos de um dispositivo de natureza essencialmente política ${ }^{14}$.
\end{abstract}

Mas o que encarado simplesmente assim como outro modo de operar analiticamente sobre a história e com ela pode sugerir apressadamente uma distância, deve ser matizado cautelosamente para cada momento distinto em que a análise histórica se dá em Foucault. Se tomarmos, por exemplo, como momentos os livros então publicados por Foucault, excluindo outros tantos textos exposições públicas, como suas aulas, é possível perceber tratamentos histórico-analíticos distintos. Roberto Machado ${ }^{15}$ mesmo reconhece que, se em linhas gerais, a genealogia parece se distanciar da arqueologia, é preciso admitir que a impressão de distância se deve mais a uma comparação entre a genealogia e aquele momento analítico da arqueologia dos saberes tal como empreendida em Les mots et les choses (1966) e L'archéologie du savoir (1969), mas que se comparado com Histoire de la folie (1961), o que se percebe é uma aproximação.

Isto deveria nos levar a concluir que há uma espécie de inflexão nietzschiana no pensamento de Foucault desde o início da década de 70 do século passado e um retorno ao modo de operar analítico de uma década antes? Não necessariamente. Para explicitar melhor meu ponto, quero tecer algumas considerações sobre o modo como em Histoire de la folie (1961) se opera a relação entre história e arqueologia. O que

\footnotetext{
${ }^{14}$ MACHADO, Ciência e Saber, 187.

${ }^{15}$ MACHADO, Ciência e Saber, 180.
}

Voluntas, Santa Maria, v.12, n.1, p. 01-16, jan./abril, 2021 
buscarei mostrar que da mesma forma que há ali elementos evidentemente nietzschianos, pode-se tomá-los na confluência com outras inspirações tanto quanto fortes.

Foi em Histoire de la folie que Foucault usou pela primeira vez em sentido técnico o termo arqueologia. Por um lado, há um sentido crítico em quer Foucault evita os modos de se fazer história da ciência como até então se fazia, a saber como uma espécie mista de hagiografia da vida dos cientistas e de suas descobertas quase que milagrosas, ou como uma coleção de episódios, carente de uma narrativa hábil em lhes apresentar no próprio devir da história. Por outro, há um sentido positivo pelo qual Foucault constitui sua concepção de história, bastante próxima àquelas da epistemologia histórica francesa ${ }^{16}$, donde uma de suas marcas características reside na tese da descontinuidade histórica. Ora, Foucault não chega a tal tese por força de sua leitura de Nietzsche, mas o contrário: é com base nessa tese da epistemologia histórica, principalmente herdada de Canguilhem, que Foucault interpreta o perspectivismo genealógico de Nietzsche. Entretanto, com bem observa mais uma vez Machado ${ }^{17}$, no que tange ao tema, Histoire de la folie é de seus livros o menos descontinuísta.

Além disso, há outro elemento forte no modo que Foucault monta sua narrativa historiográfica naquele livro de 1961. Há ali uma profunda investigação sobre as condições de possibilidade de uma modalidade discursivo-científica, aquela marcada pelo prefixo "psi" (psiquiatria, psicologia e psicanálise), condições essas que são históricas e, por isso, de natureza outra que aqueles discursos de pretensão científica. Elas se encontram no que Foucault chamou de percepção clássica da loucura; uma vez que além de sua anterioridade à qualquer conceito científico ou a qualquer teoria, é na percepção ético-social e na dicotomia estrutural entre razão e desrazão, e a partir daí

\footnotetext{
${ }^{16}$ Cf. BRAUSNTEIN, Bachelard, Canguilhem, Foucault; MACHADO, Note sur la phénoménologie dans Les mots et les choses; PORTOCARRERO, Foucault; VAN de WIELLE, L'histoire chez Michel Foucault; YAZBEK, 10 lições sobre Foucault.

${ }^{17}$ MACHADO, Note sur la phénoménologie dans Les mots et les choses, 182.
} 
entre razão e loucura, que se possibilita o nascimento da psiquiatria na Modernidade, e em nossa Contemporaneidade ${ }^{18}$. Ou como Foucault mesmo diz:

[...] a psicopatologia inutilmente tentará reencontrar essa culpabilidade misturada na doença mental, dado que ela foi posta aí exatamente por esse obscuro trabalho preparatório que se realizou no decorrer do Classicismo. Tanto é verdade que nosso conhecimento científico e médico da loucura repousa implicitamente na constituição anterior de uma experiência ética da desrazão ${ }^{19}$.

Que estranha reverberação das intuições genealógico-nietzschianas imiscuídas de outras intuições igualmente poderosas! Afinal, essas condições de possibilidade, que oscilam entre um caráter transcendental e histórico, apontam para essa outra importante fonte de inspiração, qual seja, a fenomenologia husserliana (e, desse modo, também kantiana, ainda que num sentido crítico). Claro é que, ao interpretar essa experiência ética da desrazão, o lastro nietzschiano no pensamento de Foucault se faz notar: Desde o século XIX assiste-se um esforço de reduzir toda a experiência clássica da loucura à sua consciência analítica, que consiste em tomar a loucura "reduzida apenas a fenômenos observáveis e controlados rigorosamente, ou seja, plenamente objetivada"20, mas que, todavia, "nada pôde apagar os valores dramáticos que eram dados desde a origem em seu debate" ${ }^{21}$. Nietzsche se faz presente nos dramas da história da experiência ética da desrazão pela qual ela é conjurada... Mas como entender com Nietzsche de que a mesma experiência é constituída? A mim, parece-me mais ajustado ver aí a presença do diálogo tenso entre Foucault e Husserl. Por um lado, a pesquisa ali empreendida se colocou explicitamente "sob o sol da grande pesquisa nietzschiana"22 num diapasão de tensão entre a história dialética da história (Hegel) e o trágico e a tragédia (Nietzsche), como proposto por Foucault no prefácio da primeira edição; prefácio esse que, curiosamente, foi retirado da segunda edição de Histoire de la folie. Mas como entender que a loucura como doença mental é fruto de uma

\footnotetext{
${ }^{18}$ NALLI, Há ainda alguma relevância à arqueologia?.

${ }^{19}$ FOUCAULT, Histoire de la folie, 106.

${ }^{20} \mathrm{NALLI}$, Foucault e a Fenomenologia, 168.

${ }^{21}$ FOUCAULT, Histoire de la folie, 182.

${ }^{22}$ FOUCAULT, Dits et écrits, I, 5, 162.
} 
constituição histórico-transcendental? Com Nietzsche, talvez devêssemos argumentar sob os termos entre verdade e mentira, ou conhecimento e erro, ou em termos de mnemotécnica - tendo como referência a leitura foucaultiana da genealogia nietzschiana e sua relação com a história. Mas não é esse o caso... As reverberações nietzschianas em Histoire de la folie advém principalmente de Nascimento da tragédia, da relação opositiva entre o apolíneo e o dionisíaco - "ao extremo da desordem que precede logo a ordem monótona da realização" 23 - remetendo à dualidade cosmológica do Nascimento da tragédia, como bem nota Pavini ${ }^{24}$. Por outro lado, ao insistir na história da constituição da loucura como doença mental, isto é, como objeto de um saber, Foucault começa a se distanciar das análises de Nietzsche ${ }^{25}$.

Minha hipótese é que o tema da constituição da loucura em doença mental, isto é, em objeto de saber e de ciência no curso da história, é um tema que pode ser melhor compreendido à luz da teoria husserliana da constituição. Claro que não é tão simples estipular esta hipótese, uma vez que só nos últimos trabalhos de Husserl, notadamente em $A$ crise das ciências europeias e a fenomenologia transcendental, o tema aparece de um modo mais "benevolente" e positivado, uma vez que a crise atual das ciências deve ser encarada historicamente à força de sua fundação originária e de sua finalidade histórica formando uma unidade racional: "É só em função desse olhar históricoteleológico que passado, presente e futuro fazem sentido, já que se conformam numa unidade racional - em que as disputas, as contraposições e as justaposições teóricas e filosóficas são apenas aparentes. O visar retrospectivo da história revela como mais fundamental, pela teleologia, uma 'harmonia final plena de sentido"'26.

No embate que se estabelece entre Foucault e Husserl, a teleologia para o filósofo francês - ao menos em Histoire de la folie, posto que, posteriormente e principalmente no contexto daquele texto sobre Nietzsche e a genealogia, Foucault repudiou a teleologia - ganho contornos diversos. Foucault subverte o caráter e o

\footnotetext{
${ }^{23}$ FOUCAULT, Histoire de la folie, 38.

${ }^{24}$ PAVINI, A experiência trágica da loucura em Foucault, 159.

25 PAVINI, A experiência trágica da loucura em Foucault, 161.

${ }^{26}$ NALLI, Foucault e a Fenomenologia, 171.
}

Voluntas, Santa Maria, v.12, n.1, p. 01-16, jan./abril, 2021 
estatuto da teleologia à história, pois se é possível inverter os termos da relação de modo a buscar um fim que confira um sentido harmônico, como preconizava Husserl, também não é - pelo menos em sentido ligeiramente diverso do que defendi outrora ${ }^{27}$ - a da descoberta da origem da história; ou ao menos, ao se localizar tal origem o que lá se encontra não é "a coisa em si mesma", isto é, a própria loucura, como Foucault argumenta posteriormente em L'archéologie du savoir: "Não se procura reconstituir o que podia ser a própria loucura, tal como se apresentaria inicialmente em alguma experiência primitiva, fundamental, surda, apenas articulada, e tal como teria sido organizada em seguida (traduzida, deformada, deturpada, reprimida talvez) pelos discursos e pelo jogo oblíquo, frequentemente retorcido, de suas operações"28. Aqui é possível ver a distância que separa Foucault de Husserl... Mas também de Nietzsche. Quer dizer, talvez seja ainda possível se sustentar que em Histoire de la folie a arqueologia acaba por nos fornecer alguma origem, mas esta origem não se refere a alguma coisa a um algo fora e antecedente à história, mas que só se pode dar na história da separação entre razão e loucura: "É originária a cesura que estabelece a distância entre razão e não-razão"29.

No entanto, uma vez identificada essa originária cesura, todo o percurso narrativo de Histoire de la folie aponta na direção da construção objetiva e constituição semântica da loucura com doença mental, como objeto da medicina psiquiátrica e da psicologia. Não apenas o conceito de "doença mental" é criado e transformado no nome vulgarizado a um conjunto de doenças e males morais. Foucault observa que na Idade Clássica não há uma confluência harmônica entre o conceito de doença mental, como doença da alma, e o doente mental, como categoria pela qual se especifica um determinado tipo de sujeito da desrazão, aquele que é por todos os meios conhecidos reconhecido com incurável - o que naquele contexto do internamento clássico significa apenas que é incorrigível. Portanto, para a constituição do conceito de "doença mental"

\footnotetext{
${ }^{27}$ Cf. NALLI, Foucault e a Fenomenologia, 174.

${ }^{28}$ FOUCAULT, L'archéologie du savoir, 64.

${ }^{29}$ FOUCAULT, Dits et écrits, I, 5, 159.
}

Voluntas, Santa Maria, v.12, n.1, p. 01-16, jan./abril, 2021 
e da designação do louco como doente mental, foi necessário um processo muito longo de objetivação da loucura e do louco como doença e doente; objetivação essa resultante de uma intrincada estrutura de segregação e dominação sócio-moral (por motivos, então, heterogêneos a qualquer ciência). Neste sentido é que se pode marcar a distância entre Foucault e Husserl, qual seja, a de que só a partir da dominação e conjuração asilar é que foi possível a objetivação do louco, a sua determinação precisa num corpo que não se pode corrigir, e que, por isso pode-se lhe buscar um fundamento primeiro, natural e, por isso, irrevogável e inalterável: uma doença, donde se tem o conceito peculiar de "doença mental".

A partir deste momento, o processo histórico da constituição da loucura e do louco como objetos do saber psiquiátrico e psicopatológico está garantido, não a partir de uma certeza e evidência cognitivo-intelectiva de uma consciência fundante e constituidora, como pretendia Husserl, mas por um reconhecimento moral: "este é louco, não se corrige; apenas se entende o mal que lhe acomete". E isto por que se pode dizer antes "o quão mau ele é", já que as nosografias psiquiátricas que the forjaram não modificam o modo como é percebido, não se esquece os seus "rostos já desenhados e reconhecidos da loucura"30 para desses rostos forjar uma nova memória com uma falsa valoração, como Nietzsche parece concluir acerca da origem, ou proveniência, de nossos valores morais. O que Foucault identifica parece muito mais com um complexo processo de sedimentação, camada após camada, de conhecimento psiquiátrico sobre reconhecimento moral, cujo encobrimento não é um apagamento, mas uma fundação constitutiva de uma relação de objetividade.

Nesse novo mundo da patologia, tão desacreditado e ridicularizado desde o século XIX, algo de importante está acontecendo e sem dúvida pela primeira vez na história da medicina: a explicação teórica se vê coincidir com uma dupla projeção, a do mal, pelo doente, e a da supressão do mal pelo médico. As doenças dos nervos autorizam as cumplicidades da cura. Todo um mundo de símbolos e imagens está nascendo, no qual o médico vai inaugurar, com seu doente um primeiro diálogo ${ }^{31}$.

\footnotetext{
${ }^{30}$ FOUCAULT, Histoire de la folie, 219.

${ }^{31}$ FOUCAULT, Histoire de la folie, 222.
} 
E para isso, para curar o louco o médico deverá se empenhar em corrigir o imoral ${ }^{32}$.

Isto posto, e sem querer ser exaustivo, vê-se que, mais importante que determinar as linhas de filiação de Foucault, seja com Nietzsche seja com Husserl, ou com tantos outros pensadores, o mais interessante é rastrear os pontos de cruzamento que permite compreender quem foram os contemporâneos de pensamento, os membros dessa bizarra, mas profícua e potente comunidade de pensamento em que pensadores tão distintos como Nietzsche, Husserl e Foucault fizeram parte e que permite compreender ao menos perspectivamente a proveniência (Herkunft) do pensamento foucaultiano.

\section{REFERÊNCIAS BIBLIOGRÁFICAS}

ARALDI, C. L.; VALEIRÃO, K. (orgs.). Os herdeiros de Nietzsche: Foucault, Agamben e Deleuze. Pelotas: NEPFil online, 2016.

BRAUNSTEIN, J-F. Bachelard, Canguilhem, Foucault. Le 'style français' en épistémologie, In: WAGNER, Pierre (org.). Les Philosophes et la Science. Paris : Gallimard, 2002. 920-963.

CARVALHO, A. F. Foucault: atualizador da genealogia nietzschiana. Cadernos Nietzsche. 30, 2012: 221-249.

FOUCAULT, M. Dits et écrits. Tomes I-IV. Paris: Gallimard, 1994.

FOUCAULT, M. Histoire de la folie. Paris : Gallimard, 1972.

FOUCAULT, M. L'archéologie du savoir. Paris : Gallimard, 1969.

LEBRUN, G. Note sur la phénoménologie dans Les mots et les choses. In: V.V.A.A. Michel Foucault philosophe. Paris: Seuil, 1989.

MACHADO, R. Ciência e Saber: A trajetória da arqueologia de Michel Foucault. Rio de Janeiro: Graal, 1981.

${ }^{32}$ Cf. NALLI, Curar o louco, corrigir o imoral. 
NALLI, M. Curar o louco, corrigir o imoral: A questão foucaultiana da cura em Histoire de la folie. In: LEMOS, F. C. S.; GALINDO, D. et al. Estudos com Michel Foucault: Transversalizando em Psicologia, História e Educação, Curitiba: CRV, 2015, 193-214.

NALLI, M. Há ainda alguma relevância à arqueologia? Considerações entre história dos discursos de verdade e de poder. Cadernos de Ética e Filosofia Política (USP), v. 2, 215-231, 2019.

NALLI, M. O conhecimento científico como problema: algumas notas sobre o debate HusserlFoucault. Síntese. Belo Horizonte, v. 33, n.106, 181-198, 2006.

NALLI. M. Foucault e a fenomenologia. São Paulo: Loyola, 2006.

NIETZSCHE, F. Genealogía de la moral. Un escrito polémico. Int. trad e notas de Andrés Sánchez Pascual. Madrid: Alianza Editorial, 1975.

NIETZSCHE, F. Opere. Edizione italiana diretta da G. Colli e M. Montinari. 8 vols. 1972.

PAVINI, R. A experiência trágica da loucura em Foucault: uma inspiração nietzschiana?. In: ARALDI, C. L.; VALEIRÃO, K. (orgs.). Os herdeiros de Nietzsche: Foucault, Agamben e Deleuze. Pelotas: NEPFil online, 2016. 149-170.

PINHO, L. C. A presença de Nietzsche na obra de Foucault: mais do que uma afinidade filosófica. Princípios. V. 16, n. 26, jul./dez. 2009: 167-187.

PORTOCARRERO, V. Foucault: a história dos saberes e das práticas. In: PORTOCARRERO, V. (org.). Filosofia, História e Sociologia das Ciências: Abordagens contemporâneas. Rio de Janeiro: Ed.Fiocruz, 1994.

VAN de WIELLE, J. L'histoire chez Michel Foucault: Le sens de l'archéologie. Revue Philosophique de Louvain. Louvain (Belgique), 81 (52): 601-633, 1983.

VEYNE, P. Foucault révolutionne I'histoire. In: Comment on écrit l'histoire. Paris: Seuil, 1978.

YAZBEK, A. C. A herança às avessas da fenomenologia de Husserl no pensamento de Michel Foucault: da epistemologia francesa e da arqueologia como contra-fenomenologias. Revista Ética e Filosofia Política. N. XX, vol. I, junho de 2017: 168-186.

YAZBEK, A. C. 10 lições sobre Foucault. Petrópolis: Vozes, 2015.

\section{Contribuição de autoria}

\section{1 - Marcos Nalli}

Professor de Filosofia

http://orcid.org/0000-0001-6476-1472•marcosnalli@yahoo.com

Contribuição: Único autor 


\section{Como citar este artigo}

NALLI, Marcos., Entre Nietzsche e Husserl: Foucault na encruzilhada. Voluntas Revista Internacional de Filosofia, Santa Maria, v. 12, n. 1, e05, 2021. DOI 10.5902/2179378664544. Disponível em: https://doi.org/10.5902/2179378664544. Acesso em: dia mês abreviado. ano. 